\title{
The new AIS-INGV digital ionosonde
}

\author{
Enrico Zuccheretti $\left({ }^{1}\right)$, Giuseppe Tutone $\left({ }^{1}\right)$, Umberto Sciacca $\left({ }^{1}\right)$, Cesidio Bianchi $\left({ }^{1}\right)$ \\ and Baskaradas James Arokiasamy $\left(^{2}\right)$ \\ ( $\left.{ }^{1}\right)$ Istituto Nazionale di Geofisica e Vulcanologia, Roma, Italy \\ ( ${ }^{2}$ TRIL fellow, The Abdus Salam International Center for Theoretical Physics, Trieste, Italy
}

\begin{abstract}
A new digital ionosonde called AIS-INGV (Advanced Ionospheric Sounder) was designed both for research and for routine service of HF radio wave propagation forecast. Nearly the entire system was developed in the Laboratorio di Geofisica Ambientale at the Istituto Nazionale di Geofisica e Vulcanologia (INGV), Rome. It exploits advanced techniques for signal analysis, recent technological devices and PC resources. This paper describes design concepts and performance of the new ionosonde.
\end{abstract}

Key words ionosonde - pulse compression - phase coherent integration

\section{Introduction}

Since their origin, radio and radar techniques have been used to sound the ionosphere. They were suitable both to study the higher atmosphere and to forecast the propagation conditions useful for applications on radio communications.

From 1970 onwards, modern systems have been added to the older ones: making use of analogue techniques they were able only to measure the electron density and the virtual height of the reflecting layers. The more recent and modern ionosondes are called Advanced Ionospheric Sounders (AIS). As the RF designers started using techniques such as pulse compression, coherent integration etc., the use of digital AIS reduces the transmitted power maintaining a favourable $\mathrm{S} / \mathrm{N}$ ratio. The new

Mailing address: Dr. Enrico Zuccheretti, Istituto Nazionale di Geofisica e Vulcanologia, Via di Vigna Murata 605, 00143 Roma, Italy; e-mail: zuccheretti@ingv.it sounders perform analysis on the received echo which enables the extraction of more parameters (such as polarisation conditions, electron density and doppler shift) from the echo. A more detailed review of the ionosondes evolution can be found in Davies (1990), Hunsuker (1991) and Bibl (1998).

Based on the above mentioned characteristics, a digital low power pulse compressed ionosonde was developed in the Laboratorio di Geofisica Ambientale (LGA) of the Istituto Nazionale di Geofisica e Vulcanologia (INGV), Rome. The objective of this ionosonde called AIS-INGV was to reduce the transmitted peak power (less than $250 \mathrm{~W}$ ) and consequently its weight and size, power consumption and hardware complexity.

The AIS-INGV ionosonde is completely programmable. The control, data acquisition, on-line processing and storage of the acquired data are supported by a directly interfaced PC. This ionosonde employs a 16 bit complementary phase code and exploits the most advanced HFradar techniques, such as pulse compression and phase coherent integration. The processing gain due to correlation process and phase coherent integration compensates the reduction of the transmitted power. The first prototype is capable of measuring the virtual height. This 
basic system allows future expansions like polarization information, doppler analysis, etc. This paper describes design concepts, digital signal processing and system performances of the new ionosonde AIS-INGV.

\section{System design concepts}

\subsection{Specifications}

The specifications of the new system are presented in table I. The new ionosonde has been designed and built on the base of the theory of radar systems, applied to the study of ionosphere (Skolnik, 1980, 1997; Hunsucker, 1991). Figures 2 and 3, together with table II, show the configuration of the ionosonde with arrangement of its subsystems and boards. The complete design report by Arokiasamy et al. (2002), gives a detailed description of the structure and operation of the various constitutive boards. Since a detailed analysis is beyond the scope of this paper, only a synthetic description of the ionosonde referring to fig. 1 (which is a simplified functional diagram of the whole system) will be presented here.

\subsection{General description}

In fig. 1, the ionosonde has been divided into functional blocks representing the main functions; one block does not necessarily correspond to physical blocks or circuits. The thicker lines refer to digital buses.

The blocks are grouped into two sections corresponding approximately to the transmitting and the receiving sections: on the left, there is a power amplifier (PWA), a frequency synthesiser (SYN) and the code generator (CODE GEN); on the right there is the radio receiver $(\mathrm{Rx})$, the Analog to Digital Converter (ADC) and the Digital Signal Processor (DSP). Every block is controlled by a personal computer (PC control and storage), which can store and display data. The antennas (Tx ant. and Rx ant.) complete the system.

In order to increase the signal-to-noise ratio without increasing the transmitted peak power, the pulse compression technique (encoded pulse) is applied. After the echo is received, it is compared to the transmitted code by means of a correlation process. To this purpose a digital biphase complementary code is used. It lets the RF carrier assume only two values for its phase: $0^{\circ}$

Table I. AIS-INGV ionosonde specifications.

\begin{tabular}{ll}
\hline \hline \multicolumn{1}{c}{ Parameter } & \multicolumn{1}{c}{ Requirement } \\
\hline Height range & $90 \div 750 \mathrm{~km}$ \\
Distnace resolution & $5 \mathrm{~km}$ \\
Max. peak Tx power (average power) & $250 \mathrm{~W}(5 \sim 10 \mathrm{~W})$ \\
Receiver sensitivity & $\sim-85 \mathrm{dBm}$ for 0 dB S/N \\
Input dynamic range & $\sim 80 \mathrm{~dB}(*)$ \\
Frequency range & $1 \div 20 \mathrm{MHz}$ \\
Frequency resolution (step) & $25,50,100 \mathrm{kHz}$ \\
Frequency scan duration (max.) & 3 min (with $50 \mathrm{kHz}$ step) \\
Acquisition sampling rate & $\sim 100 \mathrm{kHz}$ \\
Acquisition quantization & 8 bit \\
Storage data rate (max.) & $60 \mathrm{kbytes}$ (with $50 \mathrm{kHz}$ step)
\end{tabular}

The symbol $(*)$ indicates the maximum range of input received powers, in all possible conditions; it is not required that the system maintains the linearity over it, provided that it allows the recognition of the echo position. 


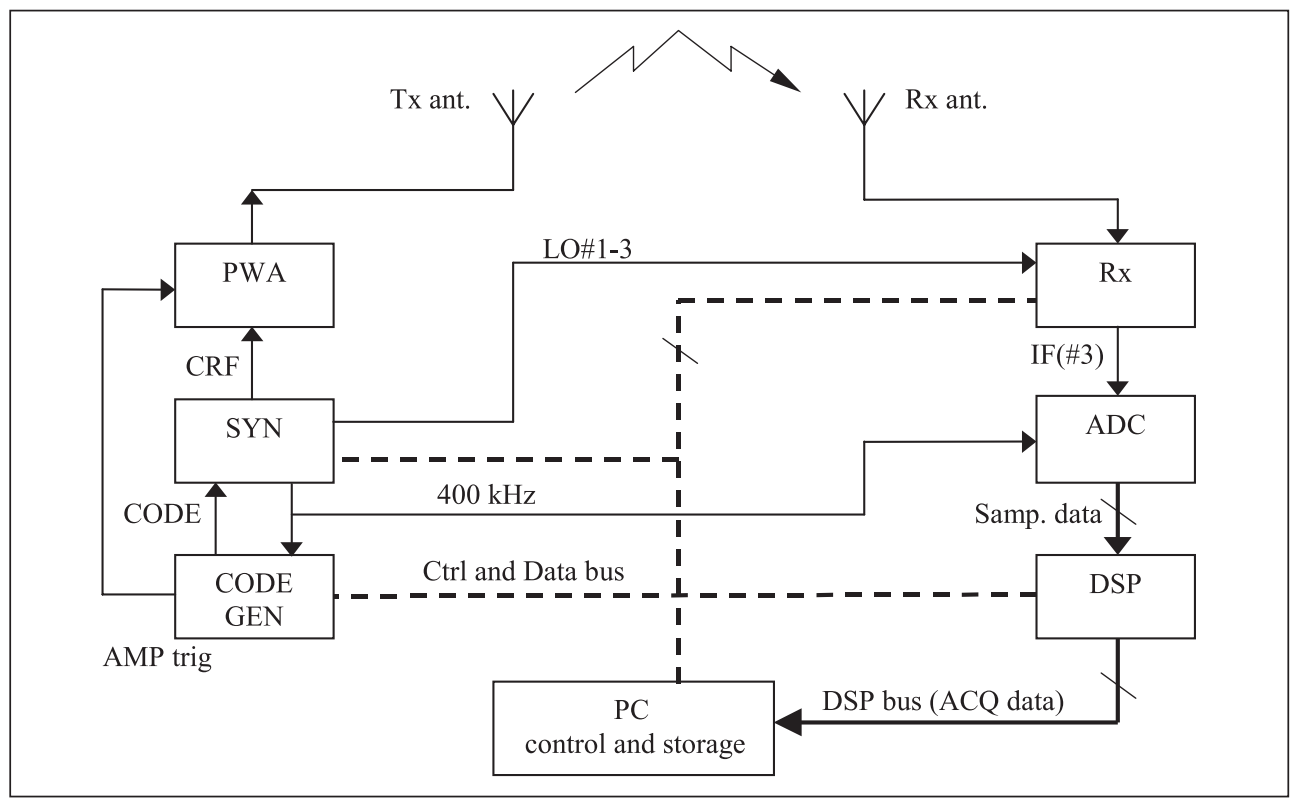

Fig. 1. Simplified functional diagram.

and $180^{\circ}$ with respect to a reference, following a pattern designed to achieve the cancellation of the correlation «sidelobes». The duration of a single phase of the code (called «sub-pulse») was set to $30 \mu$ s after the design considerations based on the specifications.

\subsection{Frequency synthesis and code generation}

The AIS-INGV adopts a receiving heterodyne system based on multiple conversions. This kind of system allows the reduction of internally generated noise due to the «image» interference. In order to make the system effective, it is important to raise the Intermediate Frequency (IF) to move the images far enough from the input passband. The IFs have been chosen at 35.9, 4.1 and $0.1 \mathrm{MHz}$. In this way, the image related to the first conversion (from 1-20 MHz to 35.9 $\mathrm{MHz}$ ) lies between 72.8 and $91.8 \mathrm{MHz}$, well beyond the RF input band. Similarly the second conversion (from 35.9 to $4.1 \mathrm{MHz}$ ) has its image at $44.1 \mathrm{MHz}$, the third (from 4100 to $100 \mathrm{kHz}$ ) at
3.9 MHz; all the images are easily removable by means of a filter before the conversion.

To accomplish such conversions, three Local Oscillators (LO) at 36.9-55.9, 40 and 4 $\mathrm{MHz}$ were devised (note that only the first has variable frequency). Since digital techniques that implement a direct synthesis of a sinusoid with a determined frequency and phase were available, it was decided to use such «DDS» devices (Direct Digital Synthesis).

Information from the received signal is extracted by means of the «quadrature» demodulation. It demands maximum phase coherence between all signals generated in the system. So, though different DDS devices are used, their reference is unique: an $\mathrm{OX} 125 \mathrm{MHz}$ quartz oscillator. All the frequencies and timing signals are derived from this unique reference oscillator. So the whole system is phase locked and a drift (few Hertz over some $\mathrm{MHz}$ ) of the reference oscillator does not affect the coherence of the system. All the DDS devices were mounted on a single board (SYN): two of them generate the first two local oscillator outputs; the third 


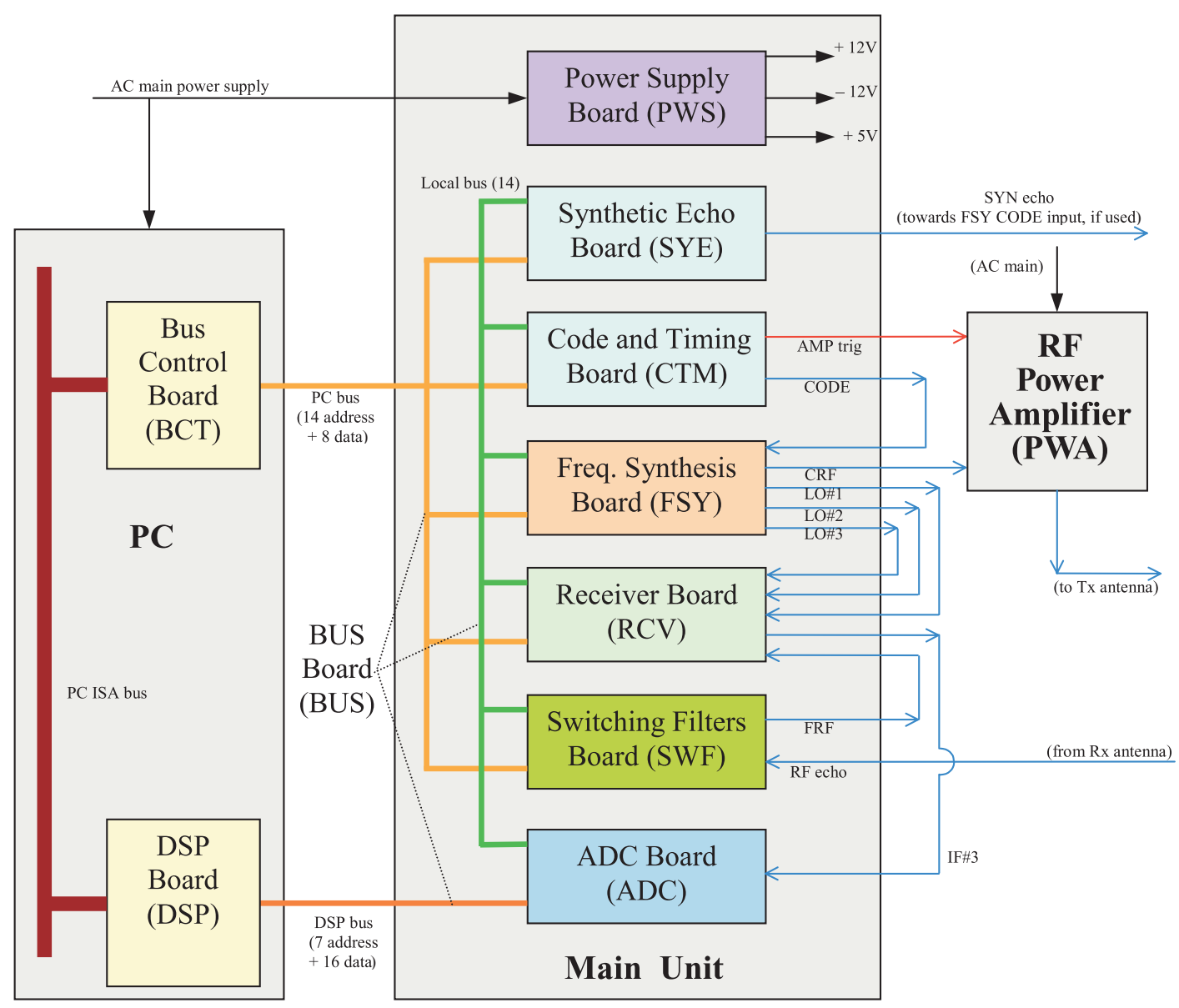

Fig. 2. The ionosonde subsystems. Interconnections (antennas not included).

generates the Tx carrier. The third local oscillator output at $4 \mathrm{MHz}$ is derived from the second at $40 \mathrm{MHz}$ by means of frequency division by ten. All the LO outputs are filtered to clean the waveforms, to make them as pure as possible. All DDS devices can output a specified frequency value by means of proper programming, coming from the PC bus.

A supplementary $400 \mathrm{kHz}$ square wave is generated from the $4 \mathrm{MHz}$; it acts as a reference for other sub-systems (e.g., the ADC), that must all be phase-locked with respect to the $125 \mathrm{MHz}$ reference. The reference clock $(400 \mathrm{kHz}$ in fig.
1) is used to create the codes ( $30 \mu$ s period corresponding to the sub-pulse length). This function was implemented in a different board, the code generator (CODE GEN). The $400 \mathrm{kHz}$ clock ( $2.5 \mu$ s period) is also used to generate the quadrature sampling clock.

The codes are implemented as digital waveforms, with the $1 \mathrm{~s}$ and the $0 \mathrm{~s}$ corresponding to the carrier phase rotations. While the proper timing is derived inside the board, the PC has only to send the exact set of $1 \mathrm{~s}$ and $0 \mathrm{~s}$. In this way, the system is very flexible; it is possible to easily change the type and length of the code. 


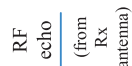
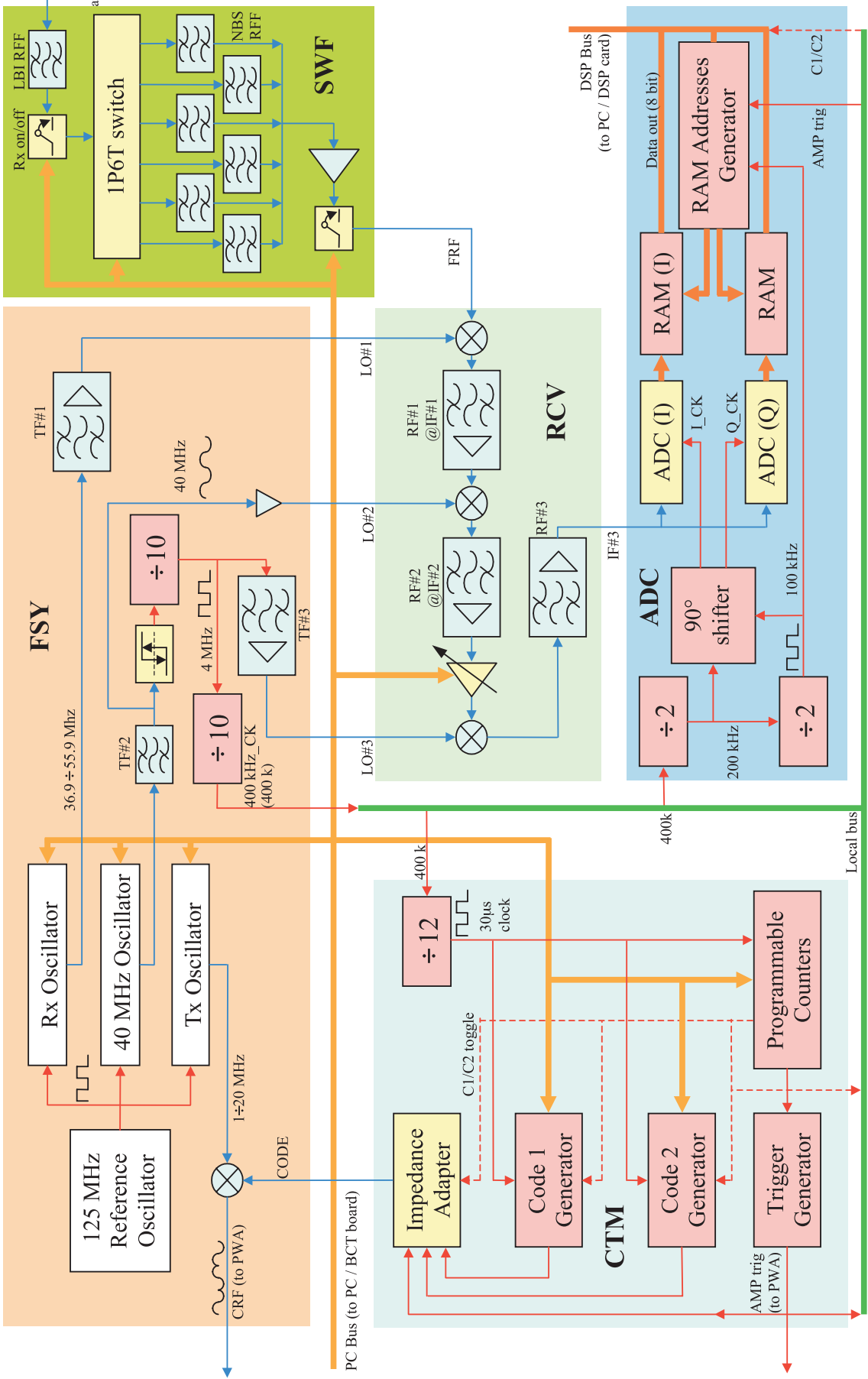

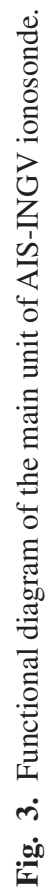


Table II. Symbols used in the block diagram.

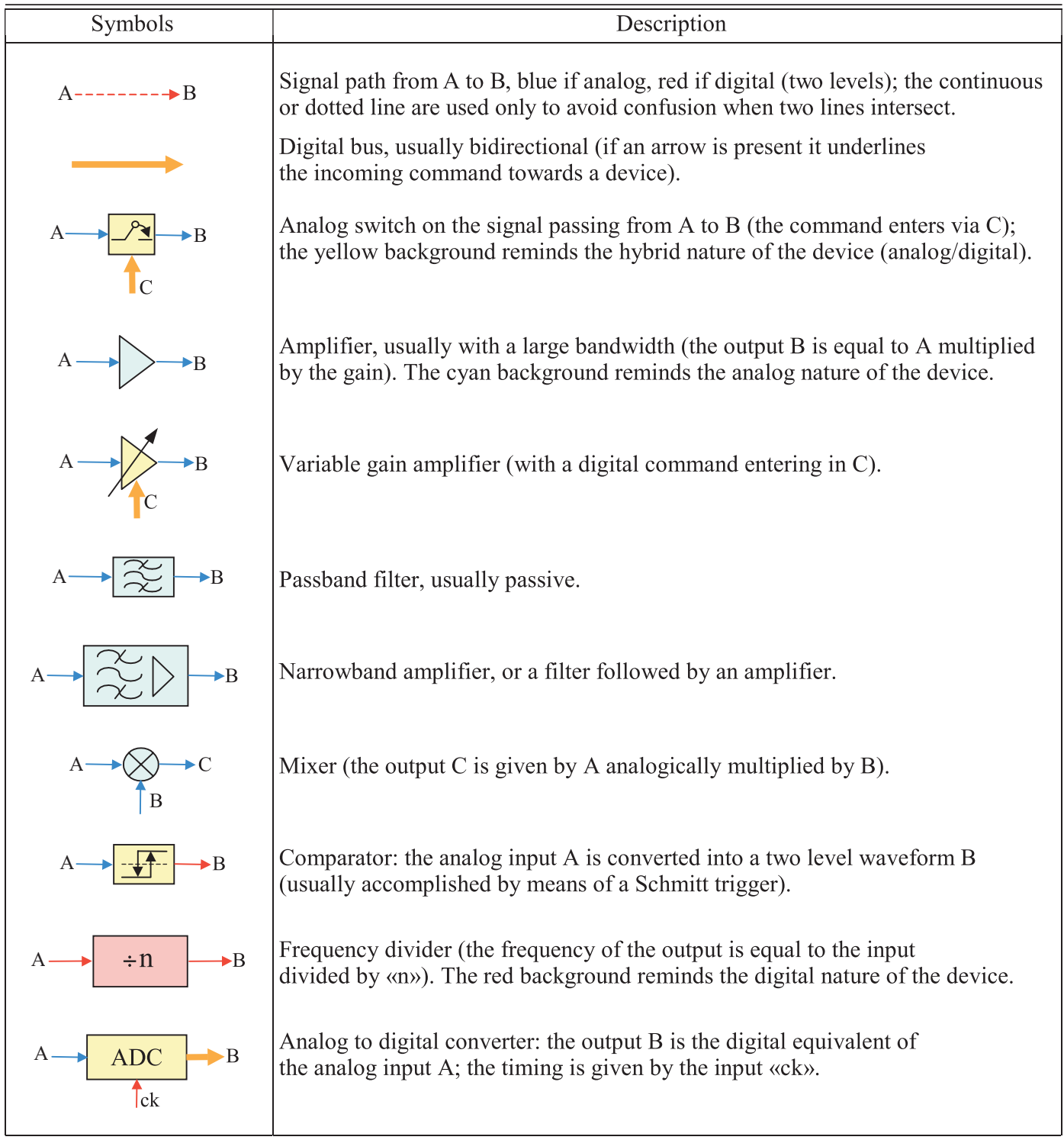

Once generated, the codes (CODE in fig. 1) are sent to the synthesiser board to modulate the RF carrier. The modulated or «coded» RF carrier (CRF in fig. 1) is then sent to the amplifier. The modulation of the RF carrier by the code could be sufficient to avoid the amplifier energy output out of the transmission phase. Anyway, in order to interdict the amplifier completely, a trigger pulse is generated inside the board (AMP trig in fig. 1). It is obtained starting from the same reference used for the code, considering that a complete Tx pulse is a multiple of 16 sub-pulses. 


\subsection{Power amplification and antenna system}

In fig. 2 the transmitting power amplifier (PWA) is considered as a separate subsystem. To increase the efficiency and reliability of the system, an industrial product was bought outside INGV. The peak power in linear conditions was set at $250 \mathrm{~W}$. The linearity specifications are not critical, because of their low impact on the useful RF band. On the other hand, the harmonics and spurious signals are to be maintained low in order to increase the power efficiency and to limit EMI.

The antenna system employed is a couple of crossed «delta» antennas, to minimise the direct coupling between the Tx and Rx (fig. 2). Each antenna has a $42 \mathrm{~m}$ base and is mounted on a single $24 \mathrm{~m}$ mast. Such an antenna type is similar to the rhombic antenna (to which it is equivalent considering the image effect due to the ground) and its impedance remains almost constant over a wide range allowing good matching with a gain (1.5-3 dB). A couple of baluns are used to match the balanced antennas with the unbalanced coaxial transmission lines.

\subsection{Receiver and $A / D$ conversion}

The demodulation is performed by means of a multiple conversion heterodyne system. The three local oscillator outputs are to be used inside the receiver as LO inputs of mixers which actually perform the conversions. Before and after the conversion filters have to be added to clean the signal from noise. Specifically, a separate board was thought to be put at the $\mathrm{Rx}$ antenna input to select a relatively narrow RF band. In detail, a preliminary filtering, wide band, is put as the first stage. It has a pass band in the ionosonde operative range (1-20 MHz) and some protection against high voltage bursts. Then six band pass filters follow; they are switchable, i.e. only one of them is actually working at a time. This combination reduces the number of RF filters maintaining the response relatively flat. The filters have different bandwidths, the lower frequency filters have a narrower bandwidth with respect to the higher frequency ones (the bandwidth is around the half of the central frequency). Switches are used in the receiving chain, in order to interdict the reception during transmission.

The output of the RF band selection filter is fed to the first mixer, inside the real receiver (the switchable filters and the receiver are two boards reported in fig. 1 as the Rx block). In the receiver chain, the three mixers are followed by filters and amplifiers. As previously mentioned, these filters limit the noise bandwidth and avoid the image interference. The last filter is the narrowest, with its pass band limited by the bandwidth of the code: $66 \mathrm{kHz}$. All hardware filters (i.e. excluding filtering accomplished by means of digital signal processing) are passive, analog, with lumped elements (capacitors and inductors).

Inside the receiver, a variable attenuator is added to increase the dynamic range. In the first realisation of the ionosonde, this feature is used only as a way to manually calibrate the system and let it work well, without dynamically changing the attenuation (and the overall gain of the receiver) to match the system to the actual ionospheric attenuation and the actual noises. The attenuator is programmable by means of the PC bus, so a future expansion of the system capability is possible. Obviously, many amplifiers are introduced in the receiving chain, to bring the signal to a good level, suitable to be processed by the following stage.

The analog to digital conversion is performed in a different board (ADC). The clock is furnished by the previously seen frequency synthesiser. Some circuitry is necessary to accomplish the «quadrature», or I-Q demodulation. Two converters sample the analog receiver output at a $100 \mathrm{kHz}$ sampling frequency (10 $\mu$ s period), but one is delayed by one fourth of a period with respect to the other $(2.5 \mu \mathrm{s})$. The sampled voltages are stored in two temporary memories, whose address is generated by a digital circuit, driven by the same $100 \mathrm{kHz}$ clock used by the ADCs. Once the acquisition process is completed (about $5.2 \mathrm{~ms}$ ) data are sent to the DSP using the same address generator.

\subsection{PC control and DSP board}

The Personal Computer (PC control and storage) supervises the operation of the whole 
system. A control program, written in a high level language, provides the interface with the operators, letting them decide the operating parameters of the soundings (starting and ending frequency, repetition rate, etc.) and displaying the ionogram while sounding. It also provides the storage of the acquired data on the local hard disk, using the internal timer to mark the time of the sounding.

An interface between the PC bus and the external ionosonde bus was introduced. A dedicated bus was designed to treat properly all control and data flowing from the PC. The control and data lines in fig. 2 are a «buffered» bus that actually brings the control signals and some data packets (e.g., the code or the words to program the Tx frequency) to the Main Unit.

A commercial Digital Signal Processing board (DSP) is employed for on-line analysis. It is programmed at a low level assembler language. The functions to be performed are better explained later. DSP output is a stream of values (an array for each frequency of sounding) representing the time domain signal amplitude. The location of the amplitude peaks is related to the heights of the reflecting layers. The PC analyses each trace, extracting the position of the peaks and displaying them on the screen. Independently of the display, the complete traces are stored on disk to be used in off-line processing (extraction of relevant parameters as critical frequencies, electron density, and so on).

\subsection{Additional blocks}

In fig. 1, some additional blocks were not included because of their minor conceptual relevance. Among these, there is a power supply $(+12 \mathrm{~V},-12 \mathrm{~V}$ and $+5 \mathrm{~V})$ to furnish the supply voltages to the various blocks, except the PC and the power amplifier that are self powered. In some cases, a $-5 \mathrm{~V}$ is generated locally in boards. In all cases, the incoming supply lines have to be filtered to reduce the electromagnetic susceptibility to duct noise.

An additional card was designed to calibrate the system during the assembly phase. It is the «synthetic echo board» (SYN ECHO), referring to its capability to output an echo-like signal. Its internal constitution is very similar to the code generator; the difference lies in the fact that the $\mathrm{RF}$ code is produced after a desired delay (user programmable) from the Tx trigger. In this way, the entire system can easily be check without transmitting signals on the air (the use of an external physical delay line would have needed a very long cable, more than $33 \mathrm{~km}$ to simulate a $50 \mathrm{~km}$ echo!). Referring to fig. 1, in this operating mode the signals are to be connected as follows: the CODE does not come from «CODE GEN» but from the «SYN ECHO», while the CRF does not go to the power amplifier but directly to the receiver through a proper attenuator.

\section{Digital Signal Processing}

Much of the on-line processing is done at software level, inside the DSP board. After reading the data stored in the ADC board, a Complex Fast Fourier Transform (CFFT) is performed. From this point on every calculation is carried out in the frequency domain (Texas Instruments, 1994; Oppenheim et al., 1999). A frequency based filtering follows the CFFT. This filtering reduces the IF bandwidth a little more; a better $\mathrm{S} / \mathrm{N}$ ratio is reached without affecting the code decoding.

A second type of filtering is then performed to reduce the high amplitude signals with respect to a reference threshold. In fact, overcoming a specified threshold is a sign that a narrow band interfering signal has passed through the last IF filter. The slight degradation of the spectrum due to the digital filtering is compensated by the great improvement of the Signal to Noise ratio.

At this point, the flow branches, for the system must perform different correlation in accordance with the transmitted code. As previously mentioned, the code is «complementary» to eliminate the sidelobes of the correlation process. Once the type of transmitted pulse is recognised, the correlation is performed. After the code 1 correlation, the system prepares itself for the reception of code 2 . The process is repeated $N$ times (where $N$ is the number of integrations) after that the two integrated correlations are summed so that the complementary code becomes effective. 
Table III. Functional blocks characteristics summary.

\begin{tabular}{|c|c|c|}
\hline Board & Parameter & Values \\
\hline FSY & $125 \mathrm{MHz}\left(f_{\text {ref }}\right)$ reference oscillator stability & $15 \mathrm{ppm}\left(0^{\circ} \div 70^{\circ}\right)+1 \mathrm{ppm}$ per year \\
\hline FSY & Rx oscillator output frequency (LO\#1) & $36.9 \div 55.9 \mathrm{MHz}$ \\
\hline FSY & Tx oscillator output frequency & $1 \div 20 \mathrm{MHz}$ \\
\hline FSY & DDS oscillators frequency resolution & $4 \cdot 10^{-9}$ of $f_{\text {ref }}(30 \mathrm{mHz})$ \\
\hline FSY & CRF output level & $-12 \mathrm{dBm}$ \\
\hline FSY & $\mathrm{TF} \# 1$ center frequency $/ 3 \mathrm{~dB}$ bandwidth $/$ min. attenuation & 46.4 MHz / $28 \mathrm{MHz} / 2 \mathrm{~dB}$ \\
\hline FSY & $\mathrm{TF} \# 2$ center frequency $/ 3 \mathrm{~dB}$ bandwidth $/ \mathrm{min}$. attenuation & $40 \mathrm{MHz} / 5 \mathrm{MHz} / 5 \mathrm{~dB}$ \\
\hline FSY & $\mathrm{TF} \# 3$ center frequency $/ 3 \mathrm{~dB}$ bandwidth $/ \mathrm{min}$. attenuation & $4 \mathrm{MHz} / 500 \mathrm{kHz} / 8 \mathrm{~dB}$ \\
\hline FSY & LO\# $1 \div 3$ output level & $+11,+8,+5 \mathrm{dBm}$ \\
\hline CTM & Pulse compression & 16 bit bi-phase complementary codes \\
\hline CTM & Sub-pulse duration & $30 \mu \mathrm{s}$ \\
\hline CTM & CODE $1 / 0 /$ Tx off voltages & $+1 /-1 / 0 \mathrm{~V}$ \\
\hline PWA & RF Power Amplifier max. gain $/ 3 \mathrm{~dB}$ band limits & $68 \mathrm{~dB} / 0.5 \div 50 \mathrm{MHz}$ \\
\hline PWA & RF Power Amplifier max. output/max. linear output & $+54 \mathrm{dBm} /+53 \mathrm{dBm}$ \\
\hline PWA & RF Power Amplifier max. spurious level (linear) & -14dBc@16 MHz,-27 dBc@2 MHz \\
\hline PWA & RF Tx residual output power out of transmission & \\
\hline SWF & LBI RFF pass band/insertion loss & $1 \div 25 \mathrm{MHz} / 3 \mathrm{~dB}$ \\
\hline SWF & $\mathrm{Rx}$ on/off switches attenuation during $\mathrm{Rx} / \mathrm{Tx}$ & $3 \mathrm{~dB} / 25 \mathrm{~dB}$ \\
\hline SWF & 1P6T insertion loss $/ \mathrm{min}$. isolation & $1 \mathrm{~dB} / 38 \mathrm{~dB}$ \\
\hline SWF & NBS RFF central frequency & $1.3-2.2-3.3-6.0-10-17 \mathrm{MHz}$ \\
\hline SWF & NBS RFF $3 \mathrm{~dB}$ bandwidth & $0.6-1.1-1.8-3.0-5.0-8.5 \mathrm{MHz}$ \\
\hline SWF & NBS RFF typ. insertion loss & $2 \mathrm{~dB}$ \\
\hline SWF & Overall SWF gain/attenuation during $\mathrm{Rx} / \mathrm{Tx}$ & $8 \mathrm{~dB}$ max. $/ 36 \mathrm{~dB}$ typ. \\
\hline $\mathrm{RCV}$ & RF\#1 center frequency/3 dB bandwidth/attenuation & $35.9 \mathrm{MHz} / 2.5 \mathrm{MHz} / 5 \mathrm{~dB}$ \\
\hline $\mathrm{RCV}$ & RF\#2 center frequency/3 dB bandwidth/attenuation & 4.1 MHz/200 kHz/4 dB \\
\hline $\mathrm{RCV}$ & RF\#3 center frequency/3 dB bandwidth/attenuation & $100 \mathrm{kHz} / 66 \mathrm{kHz} / 4 \mathrm{~dB}$ \\
\hline $\mathrm{RCV}$ & Variable gain amplifier dynamics/resolution & $30 \mathrm{~dB} / 2 \mathrm{~dB}$ \\
\hline $\mathrm{RCV}$ & Overall RCV board gain ( $0 \mathrm{~dB}$ attenuation) & $52 \mathrm{~dB}$ \\
\hline $\mathrm{ADC}$ & ADC input range & $1.55 \div 3.26 \mathrm{~V}$ \\
\hline $\mathrm{ADC}$ & ADC resolution & $8 \mathrm{bit}=6.7 \mathrm{mV}$ \\
\hline $\mathrm{ADC}$ & Sampling rate & $100 \mathrm{kHz}$ \\
\hline $\mathrm{ADC}$ & Oversampling factor (samples per sub-pulse) & 3 \\
\hline $\mathrm{ADC}$ & Demodulation system & Synchronous with quadrature carriers \\
\hline DSP & Input data stream & $290 \mathrm{~ns}$ per sample (16 bit) \\
\hline DSP & Processor speed & $40 \mathrm{MIPS}-80 \mathrm{MHz}$ \\
\hline
\end{tabular}



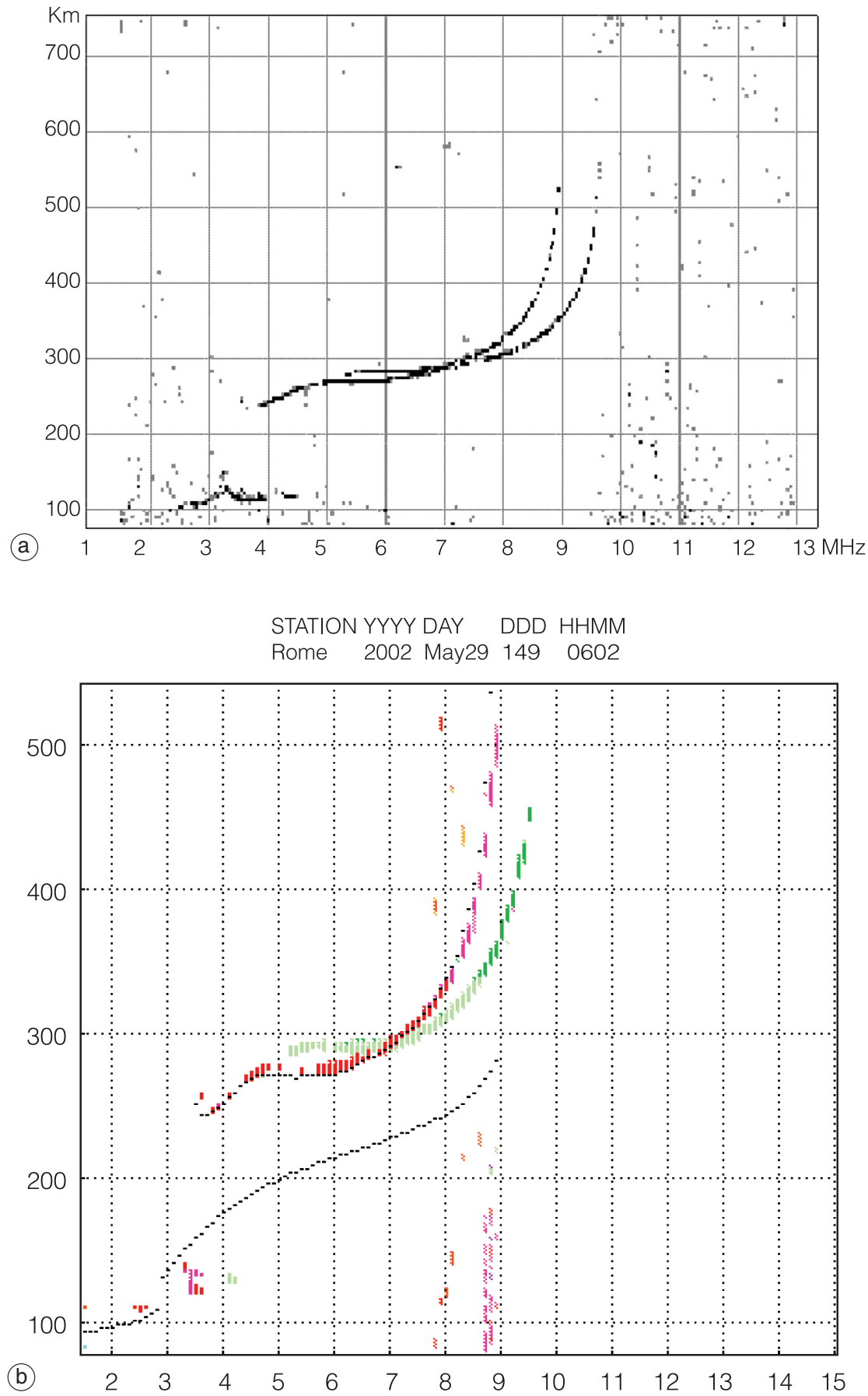

Fig. 4a,b. Ionograms recorded at 7 a.m. 2002/5/29: a) AIS-INGV ionosonde; b) other digital ionosonde. 


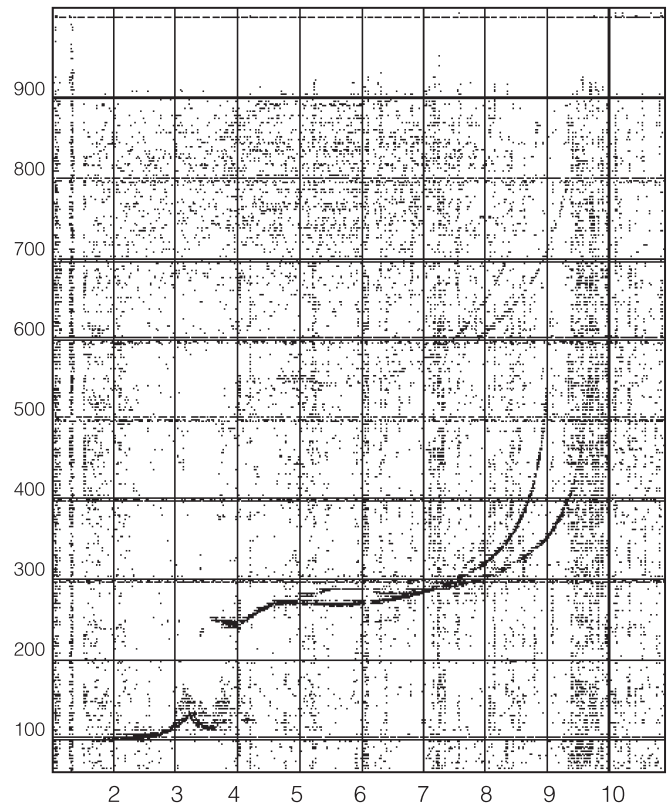

Fig. 4c. Ionogram recorded at 7 a.m. 2002/5/29: other analog ionosonde.

This phase coherent integration of the received signal is a powerful technique, because random noises are partially cancelled while the in-phase signals are amplified. The processing gain depends on the number of integrations $N$ and this integration remains effective in accordance with the ionospheric coherence time. Lastly an inverse CFFT is performed, the amplitude of the signal is computed and the controlling PC is called, so that it can store and display the data. The processing gain, correlation and phase coherent integration, is about $25 \mathrm{~dB}$.

\section{System performance and conclusions}

After the manufacturing and assembling of the boards and subsystems, tests were done, determining the performance values reported in table III. Unless differently stated all analog lines are matched to $50 \Omega$ impedance, all digital levels are TTL compatible.
The main unit absorbs less than $30 \mathrm{~W}$ of electric power (excluding the power amplifier and the PC) and the weight of the main unit is $9 \mathrm{~kg}$. Total weight and power consumption depend on the particular PC (with monitor) and power amplifier used to complete the system. At the present stage the total volume is limited approximately: $50 \mathrm{~cm}$ width, $50 \mathrm{~cm}$ depth, $80 \mathrm{~cm}$ height.

The ionosonde system has been tested for months, producing ionograms of good quality, comparable with ionograms recorded by other ionosondes. Some results will be presented, making comparisons with the two ionosonde working at INGV. In all ionograms on the horizontal axes there are the frequencies in $\mathrm{MHz}$, while the units on the vertical axes are $\mathrm{km}$; they were scaled graphically and placed in the pages to allow an easy comparison among scales; all soundings were performed in the Rome ionospheric observatory.

Figure 4a is a ionogram recorded by the AISINGV ionosonde; figs. $4 \mathrm{~b}$ and $4 \mathrm{c}$ are ionograms recorded by a digital and an analogue ionosonde respectively. The soundings were performed within a few minutes around 7.00 a.m. (local time).

Figure 5a,b show another sample of ionograms recorded by the AIS-INGV ionosonde and another digital ionosonde.

The shown ionograms were chosen as representative of the ionograms recorded by the various ionosondes; the deviations from the «normal» cases (the ones shown) are rare. It is possible to note the good quality of the ionograms recorded by the AIS-INGV ionosonde, accompanied by a good background noise level (compared to analog ionosonde). For some conditions, the AIS-INGV ionosonde is even better than the digital ionosonde used or comparison, e.g., at the lower frequencies ( $E$ layer).

These results encourage us to improve the performance of the ionosonde; some areas in which such improvements may occur are: the new functions to recognise the polarization of the echo, doppler analysis, improvement in $\mathrm{S} / \mathrm{N}$ ratio and digital signal processing using a floating point processor and the software adaptation for remote access. 
(a)

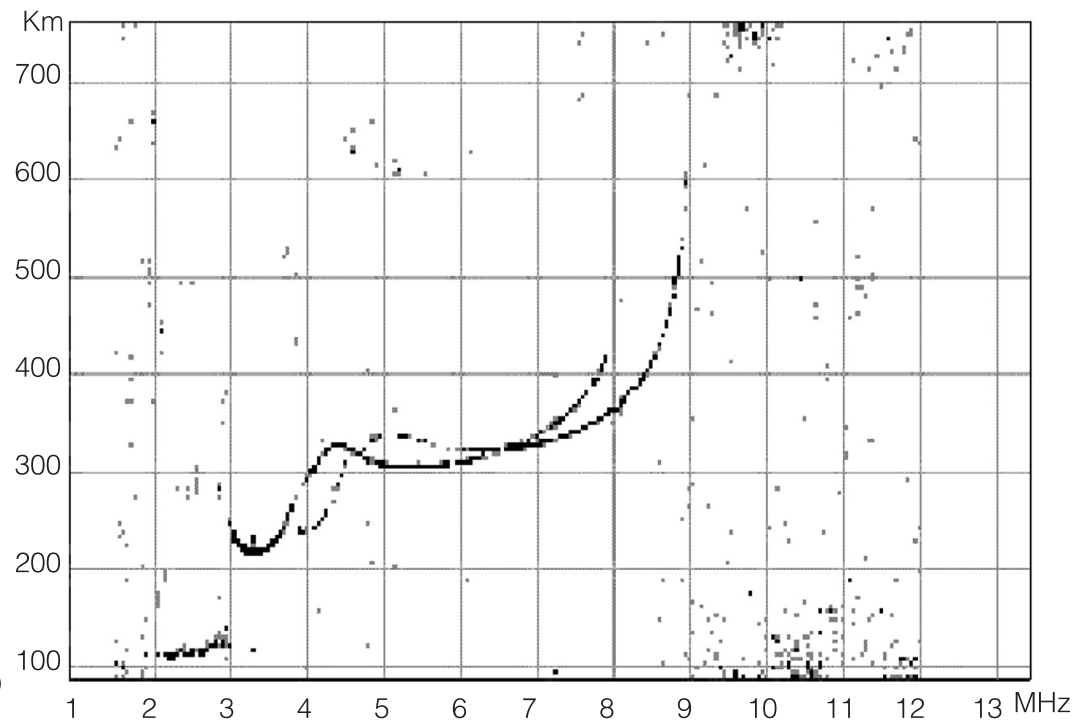

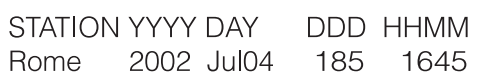

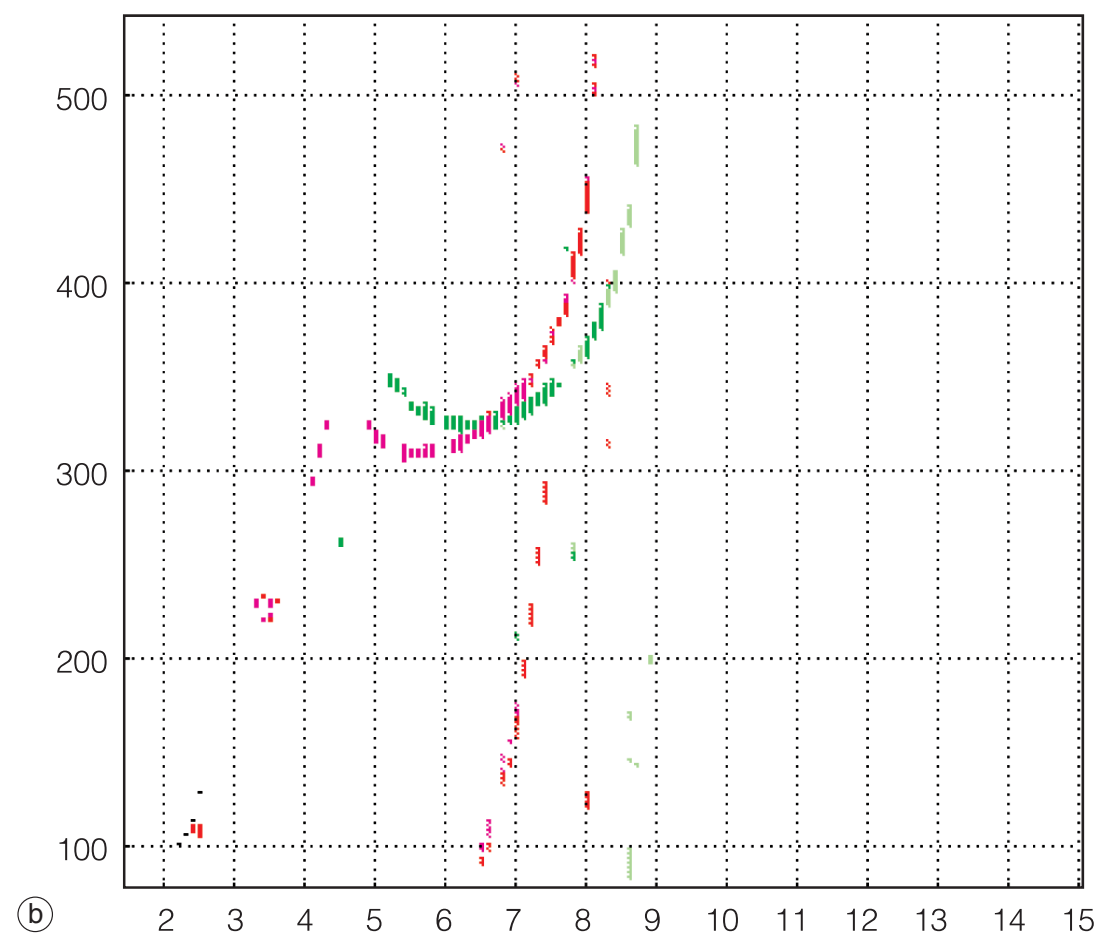

Fig. 5a,b. Ionograms recorded at 5.45 p.m. 2002/5/29: a) AIS-INGV ionosonde; b) other digital ionosonde. 


\section{REFERENCES}

AROKIASAMy, B.J., C. BiAnChI, U. SCiacca, G. TUtone, E. ZUCCHERETTI (2002): The new AIS-INGV digital ionosonde design report, INGV Internal Technical Note.

BIBL, K. (1998): Evolution of the ionosonde, Ann. Geofis., $41(5 / 6), 667-680$.

DAVIES, K. (1990): Ionospheric Radio (P. Peregrinus Ltd., London), pp. 580.

HUNSUCKER, R.D. (1991): Radio technique for probing the terrestrial ionosphere, in Physics and Chemistry in Spa$c e$, edited by M.C.E. HubER, L.J. LANZEROTTI and D. STOFFLER (Springer-Verlag, Berlin Heidelberg), vol. 22.
OPPENheIM V.A,. W.R. SCHAFER, J.R. BUCK (1999): Discrete-Time Signal Processing (Prentice Hall, New Jersey), 2nd edition, pp. 870.

SKOLNIK, M.I. (1980): Introduction to Radar Systems (Mc Graw-Hill, New York), pp. 422.

SKOLNIK, M.I. (1990): Radar Handbook (Mc Graw-Hill, New York), pp. 1200.

TEXAS InstrumenTS (1994): Digital Signal Processing Applications with the TMS320 Family (Prentice-Hall).

(received January 7, 2003;

accepted April 28, 2003) 